University of Wollongong

Research Online

Faculty of Engineering and Information

Faculty of Engineering and Information

Sciences - Papers: Part B

Sciences

2018

\title{
The effects of forced interpass cooling on the material properties of wire arc additively manufactured Ti6Al4V alloy
}

\author{
Bintao Wu \\ University of Wollongong, bw677@uowmail.edu.au \\ Zengxi Stephen Pan \\ University of Wollongong, zengxi@uow.edu.au \\ Donghong Ding \\ Foshan Universiyt, donghong@uow.edu.au \\ Dominic Cuiuri \\ University of Wollongong, dominic@uow.edu.au \\ Hui Jun Li \\ University of Wollongong, huijun@uow.edu.au
}

See next page for additional authors

Follow this and additional works at: https://ro.uow.edu.au/eispapers1

Part of the Engineering Commons, and the Science and Technology Studies Commons

Research Online is the open access institutional repository for the University of Wollongong. For further information contact the UOW Library: research-pubs@uow.edu.au 


\title{
The effects of forced interpass cooling on the material properties of wire arc additively manufactured Ti6AI4V alloy
}

\author{
Abstract \\ To achieve improved microstructure and mechanical properties, an innovative wire arc additive \\ manufacturing (WAAM) process with forced interpass cooling using compressed $\mathrm{CO}_{2}$ was employed in \\ this study to fabricate Ti6Al4V thin-walled structures. The effects of various interpass temperatures and \\ rapid forced cooling on deposition geometry, surface oxidation, microstructural evolution, and mechanical \\ properties of the fabricated part were investigated by laser profilometry, optical microscopy (OM), \\ scanning electron microscopy (SEM), hardness testing and mechanical tensile testing. Results show that \\ the microstructural evolution and mechanical properties of the deposited metal are not greatly affected \\ by an increasing interpass temperature, however, the deposited wall tends to be widened, flattened and \\ exhibit increased surface oxidation through visible coloration. When rapid forced cooling using $\mathrm{CO}_{2}$ is \\ used between deposited layers, slightly higher hardness values and increased strength can be obtained. \\ This is mainly attributed to the combined effects of less surface oxide and high density dislocation \\ caused by the generation of large amounts of fine-grained acicular $\alpha$ within the microstructure. \\ Furthermore, forced interpass cooling not only improves deposition properties, but also promotes \\ geometrical repeatability and also improved manufacturing efficiency through the reduction of dwell time \\ between deposited layers. \\ Disciplines \\ Engineering | Science and Technology Studies

\section{Publication Details} \\ Wu, B., Pan, Z., Ding, D., Cuiuri, D., Li, H. \& Fei, Z. (2018). The effects of forced interpass cooling on the \\ material properties of wire arc additively manufactured Ti6Al4V alloy. Journal of Materials Processing \\ Technology, 258 97-105.

\section{Authors} \\ Bintao Wu, Zengxi Stephen Pan, Donghong Ding, Dominic Cuiuri, Hui Jun Li, and Zhenyu Fei
}




\title{
The effects of forced interpass cooling on the material properties of wire arc additively manufactured Ti6Al4V alloy
}

\author{
Bintao Wu ${ }^{\mathrm{a}}$, Zengxi Pan ${ }^{\mathrm{a} *}$, Donghong Ding ${ }^{\mathrm{b}}$, Dominic Cuiuri ${ }^{\mathrm{a}}$, Huijun $\mathrm{Li}^{\mathrm{a}}$, Zhenyu \\ $\mathrm{Fei}^{\mathrm{a}}$ \\ a. School of Mechanical, Materials, Mechatronic and Biomedical Engineering, University of \\ Wollongong, Wollongong NSW 2522, Australia \\ b. School of Mechatronic Engineering, Foshan University, Foshan Guangdong 528000, China
}

\section{ABSTRACT}

To achieve improved microstructure and mechanical properties, an innovative wire arc additive manufacturing (WAAM) process with forced interpass cooling using compressed $\mathrm{CO}_{2}$ was employed in this study to fabricate Ti6Al4V thin-walled structures. The effects of various interpass temperatures and rapid forced cooling on deposition geometry, surface oxidation, microstructural evolution, and mechanical properties of the fabricated part were investigated by laser profilometry, optical microscopy (OM), scanning electron microscopy (SEM), hardness testing and mechanical tensile testing. Results show that the microstructural evolution and mechanical properties of the deposited metal are not greatly affected by an increasing interpass temperature, however, the deposited wall tends to be widened, flattened and exhibit increased surface oxidation through visible coloration. When rapid forced cooling using $\mathrm{CO}_{2}$ is used between deposited layers, slightly higher hardness values and increased strength can be obtained. This is mainly attributed to the combined effects of less surface oxide and high density dislocation caused by the generation of large amounts of fine-grained acicular $\alpha$ within the microstructure. Furthermore, 
forced interpass cooling not only improves deposition properties, but also promotes geometrical repeatability and also improved manufacturing efficiency through the reduction of dwell time between deposited layers.

Key words: Wire Arc Additive Manufacturing (WAAM); Ti6Al4V; Interpass temperature; $\mathrm{CO}_{2}$ gas interpass cooling; Material properties.

*Corresponding author:

Zengxi Pan; Tel: +61-2-42215498; Email address: zengxi@uow.edu.au; (Z. Pan).

\section{Introduction}

In recent years, wire arc additive manufacturing (WAAM) has increasingly attracted attention from the industrial manufacturing sector due to its ability to create large metal components with high deposition rate, low equipment cost, high material utilization, and consequent environmental friendliness (Williams et al., 2016). So far several engineering materials, including titanium alloys, aluminium alloys, nickel-based superalloys and low-carbon steels have been successfully applied to produce full density parts (Herzog et al., 2016). Titanium alloys, especially Ti6Al4V, attract significant research interest from the proponents of additive manufacturing due to its frequent use in aerospace applications, where conventional subtractive fabrication methods for these components often suffer from very low fly-to-buy ratios (Pan et al., 2018).

For a Ti6Al4V component that is produced by WAAM, the microstructures are complex, often varying spatially within the deposition due to its complex thermal 
history that involves alternate re-heating and re-cooling cycles (Collins et al., 2016). Even for adjacent regions within a deposit, differences in microstructure still exist, ultimately bringing inhomogeneous material performance to the component. To date, numerous investigations have been carried out to reveal microstructural formation mechanisms through the investigation of thermal history in WAAM deposition, with the aim of offering some helpful directions to solve these problems. For example, $\mathrm{Wu}$ et al. (2017) observed that heat accumulation during additive fabrication has significant effects on the stability of gas tungsten wire arc additive manufactured Ti6Al4V alloy, which demonstrates the importance of in-process temperature monitoring and control. Suryakumar et al. (2013) claimed that depending on the thermal cycles in WAAM-fabricated steel, coarse grained microstructures with inhomogeneous hardness are formed along the building direction. Foster et al. (2017) reported that increasing dwell time result in a slight decrease in the alpha lath widths and a more noticeable decrease in the width of prior beta grains during manufactured Ti6Al4V using directed energy deposition process. These findings suggest that there is a tremendous need for microstructural optimization through improvements in process control of additive manufacturing.

As mentioned above, the solidification microstructure, including grain size and morphology, is essentially dependent on the thermal history during the manufacturing process. That is to say, if the thermal state during deposition is properly controlled, the desired microstructures and resulting mechanical properties with acceptable performance can be achieved. Based on this interpretation, recent studies by Henckell 
et al. (2017) have attempted to employ additional cooling gas for WAAM fabrication of low alloy steel components. Interestingly, applying an additional post-weld cooling gas of nitrogen with $5 \%$ hydrogen improves both the layer geometry and mechanical properties through grain refinement and homogenous hardness. Additionally, the different gas types used in deposition produce varying material properties, and further investigations were proposed that would employ carbon dioxide or pure nitrogen. It is well known that $\mathrm{CO}_{2}$ gas cooling is commonly employed in Low Stress No Distortion (LSND) welding to reduce residual stress and deformation. According to Holder et al. (2011), the heat affect zones of DH-36 steel welds show significant changes in hardness when subjected to conventional gas metal arc welding and LSND welding processes. Based on such findings, if $\mathrm{CO}_{2}$ gas is used to dynamically cool the deposits during the WAAM process, it is possible that similar effects on material properties can be obtained.

In this study, gas tungsten arc welding based WAAM (GT-WAAM) with forced interpass cooling using compressed $\mathrm{CO}_{2}$ gas is applied to Ti6Al4V, with the aim of improving material properties. The effects on surface oxidation, geometrical features, microstructural evolution, and mechanical properties are investigated through the use of WAAM with and without $\mathrm{CO}_{2}$ gas cooling. Firstly, the interpass temperature is controlled (i.e. allowed to decrease through natural convection and conduction before deposition of the next layer) to a number of constant values, aiming at an understanding of the effects of interpass temperature on the targeted deposition properties. Subsequently, forced interpass cooling is implemented, aimed at an 
improvement of material properties. A detailed analysis and discussion of the results is used to assess the possibilities for controlling the properties of WAAM-fabricated Ti6A14V by using this method.

\section{Experimental Procedures}

\subsection{Experiment setup}

The apparatus consists of a 200 A-rated GTAW power source, "cold" wire feeder, water cooling unit and travel mechanism, as shown in Fig.1.An IR pyrometer was used to measure the in-situ interpass temperature, thereby controlling the dwell time between deposition of layers. The feedstock used in this study was ASTM B863 grade 5 Ti6Al4V wire with a diameter of $1.2 \mathrm{~mm}$, deposited onto a Ti6Al4V substrate with dimensions of $200 \mathrm{~mm} \times 150 \mathrm{~mm} \times 6 \mathrm{~mm}$ that conforms to ASTM B265 specification. The chemical compositions are listed in Table 1. Three straight wall structures were fabricated at respective interpass temperatures of $100{ }^{\circ} \mathrm{C}, 200{ }^{\circ} \mathrm{C}$, and $300{ }^{\circ} \mathrm{C}$ using the GT-WAAM system with localized gas shielding. The process parameters are provided in Table 2. Welding grade argon (99.995\% purity) was used as the shielding gas for both GTAW torch and trailing shield.

Table 1 Chemical composition of Ti6Al4V (wt.\%).

\begin{tabular}{ccccccccc}
\hline Composition & $\mathrm{Al}$ & $\mathrm{V}$ & $\mathrm{C}$ & $\mathrm{Fe}$ & $\mathrm{H}$ & $\mathrm{N}$ & $\mathrm{O}$ & $\mathrm{Ti}$ \\
\hline Wire (ASTM B863) & 6.20 & 4.0 & 0.08 & 0.40 & 0.015 & 0.05 & 0.20 & Bal. \\
\hline Substrate (ASTM B265) & 6.10 & 4.0 & 0.08 & 0.30 & 0.015 & 0.03 & 0.20 & Bal. \\
\hline
\end{tabular}




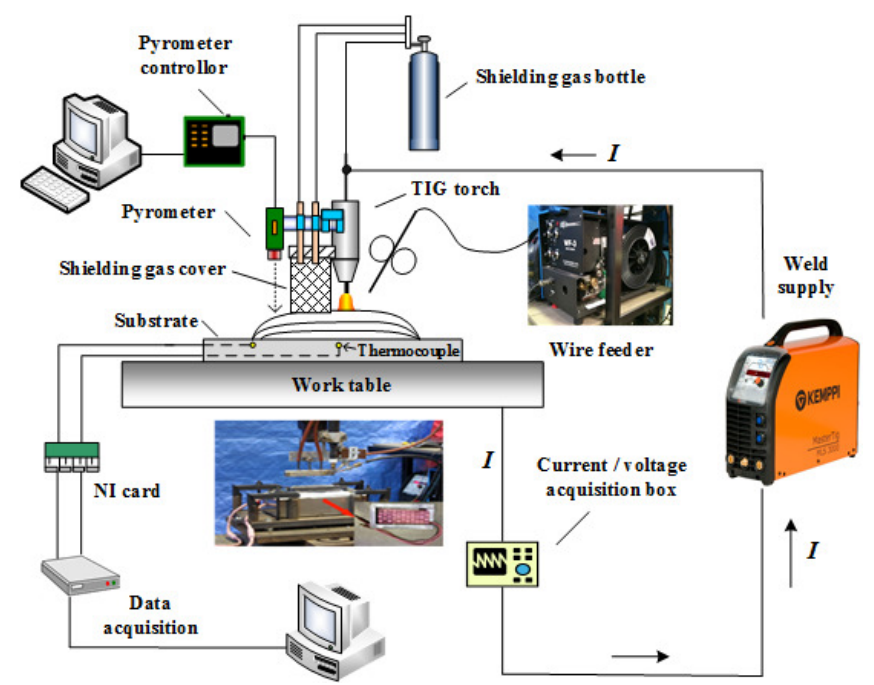

Fig.1 Schematic diagram of the GT-WAAM system

Table 2 Process parameters for WAAM deposition

\begin{tabular}{lll}
\hline Process parameters & Details & \\
\hline Deposition power & Current & $110 \mathrm{~A}$ \\
\hline & Arc voltage & $13 \mathrm{~V}$ \\
\hline Speed & Travel speed & $95 \mathrm{~mm} / \mathrm{min}$ \\
\hline & Wire feed speed & $820 \mathrm{~mm} / \mathrm{min}$ \\
\hline Distance and angle & Electrode to workpiece & $3 \mathrm{~mm}$ \\
\hline & Electrode to filler wire & $60^{\circ}$ \\
\hline Flow rate(argon) & GTAW torch & $15 \mathrm{~L} / \mathrm{min}$ \\
\hline & Trailing shield & $10 \mathrm{~L} / \mathrm{min}$ \\
\hline Time & Post flow duration & $35 \mathrm{~seconds}$ \\
\hline
\end{tabular}

\subsection{Forced interpass cooling}

In order to evaluate the effectiveness of forced interpass cooling, a commercially-available $\mathrm{CO} 2$ cooling spray nozzle was fitted to the GTAW torch as shown in Fig.2. A flow rate of $215 \mathrm{~g} / \mathrm{min}$ was used to deliver a stable $\mathrm{CO}_{2}$ cooling stream, according to the manufacturer's specifications. The cooling spray was initiated after deposition of each layer was completed in order to avoid arc disruption caused by the relatively turbulent $\mathrm{CO}_{2}$ flow. Cooling flow was stopped when the interpass temperature decreased to room temperature. 


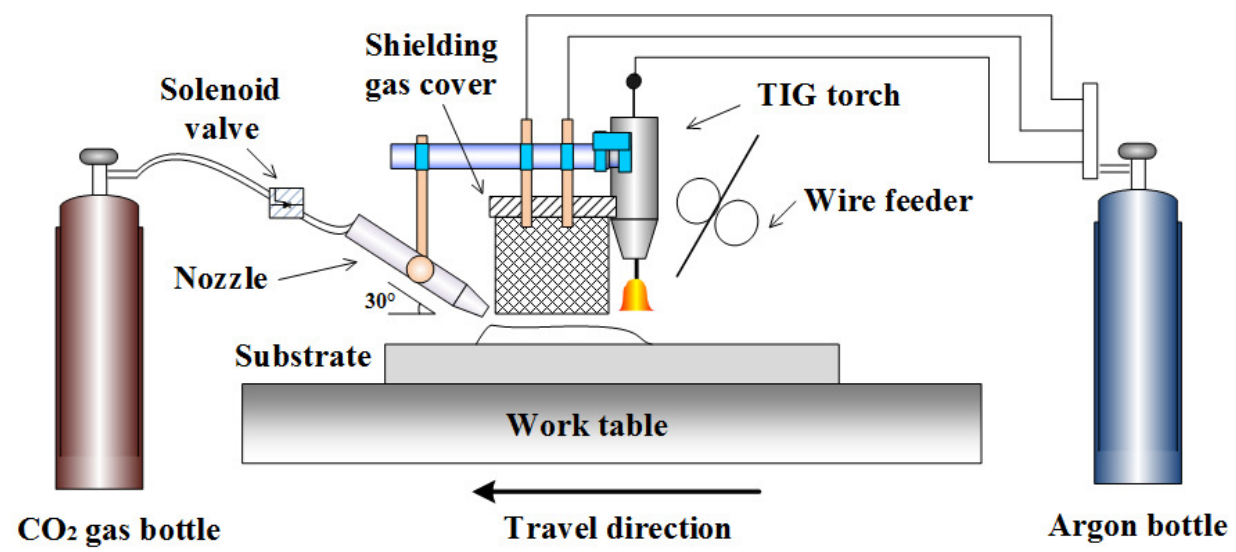

Fig.2 Schematic diagram of the GT-WAAM deposition system with forced interpass cooling

\subsection{Material characterization techniques}

Both metallographic specimens and mechanical test samples were extracted from the fabricated Ti6Al4V walls for further investigation. The metallographic specimens were hot mounted, ground and polished according to standard procedures, and then etched in Kroll's reagent containing $2 \%$ vol $\mathrm{HF}, 6 \%$ vol $\mathrm{HNO}_{3}$ with balance $\mathrm{H}_{2} \mathrm{O}$. The macrostructures were examined using a Leica M205A deep field stereoscopic microscope and the microstructures were observed using a Leica DMR optical microscope (OM). Vickers hardness testing was performed with a DuraScan 70 automatic hardness tester using a test load of $100 \mathrm{~g}$ and a dwell time of $15 \mathrm{~s}$ according to ASTM: F2924 standard. Tensile tests were carried out at room temperature at a constant crosshead displacement rate of $0.4 \mathrm{~mm} / \mathrm{min}$ using a MTS370 universal testing machine. The tensile test samples extracted from the fabricated walls are shown in Fig.3. 


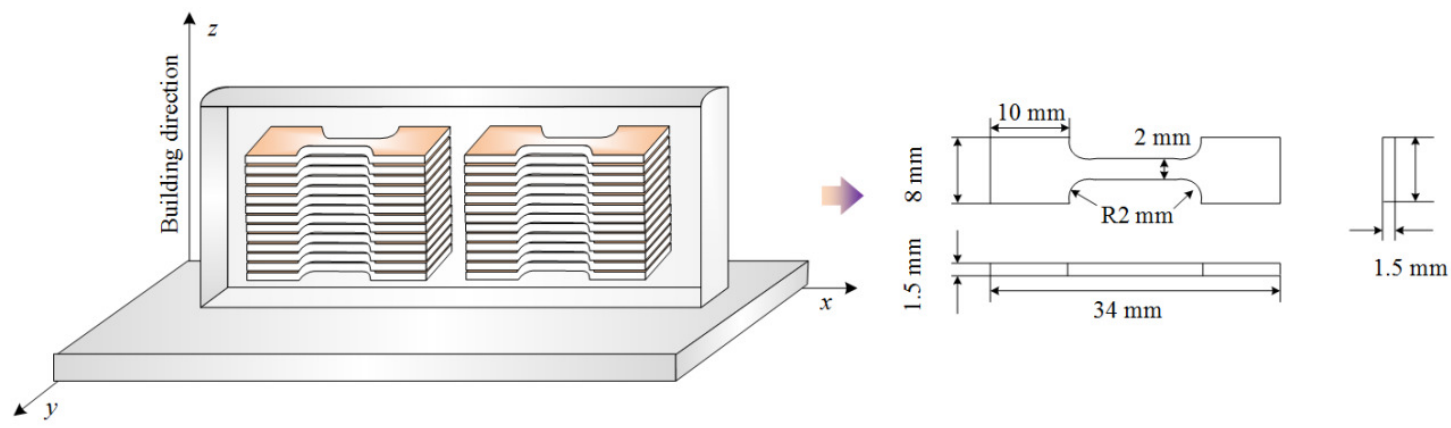

Fig.3 Schematic diagram of extracted tensile samples

\section{Results}

\subsection{Deposition geometry}

Fig.4 shows the dimensions of WAAM-fabricated Ti6Al4V walls at different interpass temperature. When the interpass temperature increases from $100{ }^{\circ} \mathrm{C}$ to $300{ }^{\circ} \mathrm{C}$, the height of the deposited wall is reduced by $11.7 \%$, whereas its width increases to $12.2 \%$. Interpass temperature has a significant effect on build geometry, even though all other process parameters are unchanged, including the number of layers. Also, the dimensions of the wall deposited using forced interpass cooling are almost identical to those of the wall built with an interpass temperature of $100{ }^{\circ} \mathrm{C}$. This indicates that forced interpass cooling not only reduces the build time, but also has the advantage of maintaining deposition accuracy.

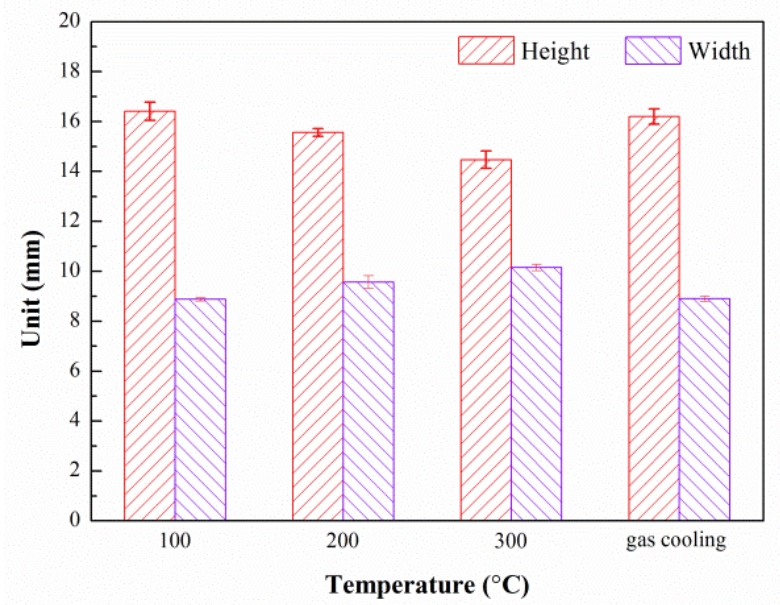

Fig.4 Effect of interpass temperature on wall dimensions 


\subsection{Surface oxidation}

The images in Fig.5 show that different degrees of surface oxidation can be observed at various interpass temperatures. For Fig.5 (a), the interpass temperature is allowed to return to $100{ }^{\circ} \mathrm{C}$ through natural convective and conductive cooling. The initially low temperature at the start of the next deposited layer essentially eliminates the effects of heat input from the newly deposited layer, so the surface of fabrication shows a clean surface with only a very slight sign of oxidation as indicated by the light straw color. As the interpass temperature is increased from $100{ }^{\circ} \mathrm{C}$ to $200{ }^{\circ} \mathrm{C}$ and then $300{ }^{\circ} \mathrm{C}$, more surface oxidation is generated, and the surface colour changes from light straw to dark blue and then powdery grey, indicating unacceptably high levels of surface contamination. For the component produced with forced interpass cooling, Fig.5(d) shows that the surface has only a small amount of oxidation as indicated by coloration, and possibly better than that of deposition with a naturally-cooled interpass temperature of $100{ }^{\circ} \mathrm{C}$. The potentially better result with forced cooling may be due to superior cooling of the zone beyond the uppermost layer. This would allow the heat input from the newly deposited layer to be better absorbed by the specific heat capacity of the previously deposited material, keeping the surface temperature sufficiently low to avoid absorption of atmospheric oxygen after the shielding gas is turned off at the end welding. These results suggest that rapid $\mathrm{CO}_{2}$ gas cooling during the dwell interval is beneficial for avoiding post-deposit oxidation titanium when using WAAM with localized gas shielding in an otherwise open atmosphere. 


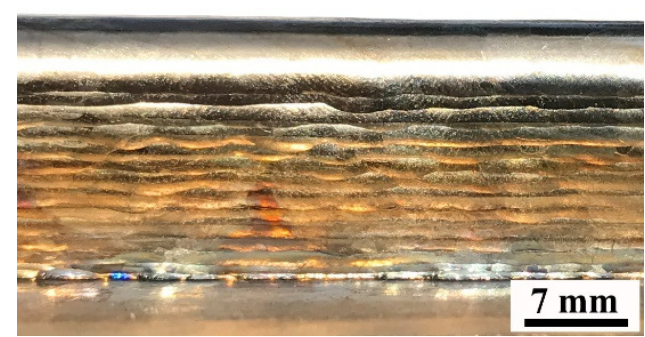

(a)

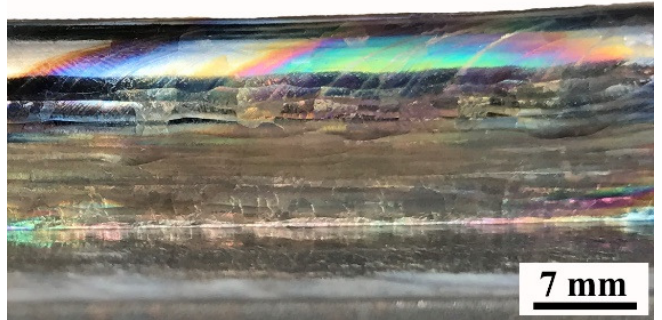

(c)

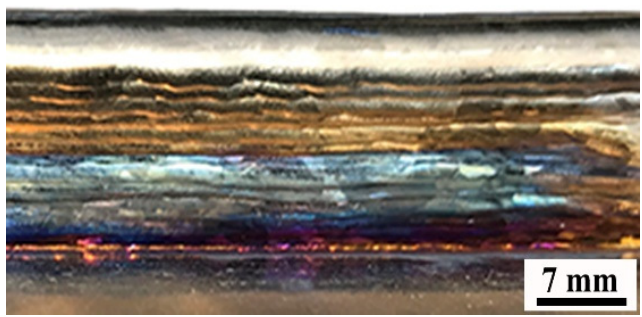

(b)

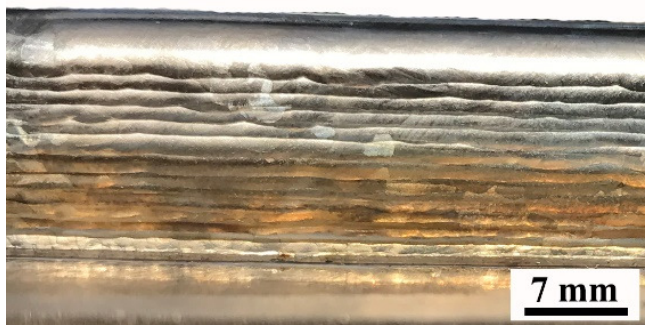

(d)

Fig.5 The surface appearance of Ti6Al4V parts fabricated at different process conditions: (a) $100{ }^{\circ} \mathrm{C}$; (b) $200{ }^{\circ} \mathrm{C}$; (c) $300{ }^{\circ} \mathrm{C}$; (d) Forced cooling with $\mathrm{CO}_{2}$ gas

\subsection{Macrostructure}

Fig.6 shows the cross-section macrograph of the four as-fabricated Ti6Al4V walls. Three distinct regions are discernible on the etched cross-section: the substrate regions with concave bands $\left(\mathrm{R}_{3}\right)$, the bottom regions with parallel bands $\left(\mathrm{R}_{1}\right)$ and the top regions $\left(\mathrm{R}_{2}\right)$ with convex bands.

The concave band is apparently determined by the field of heat affected zone which expands at high interpass temperature on the substrate. However, when the interpass temperature is controlled at $300{ }^{\circ} \mathrm{C}$, there are no obvious convex bands and the microstructure produced in the substrate region is homogeneous, possibly attributing to the large grain growth at low cooling rates. For the parallel bands and convex bands, which are present in the majority of the deposits, their number varies with interpass temperature. Fig.7 further displays the proportion ratio $\left(\mathrm{R}_{1} / \mathrm{R}_{2}\right)$ between two types of bands at different process conditions. It can be observed that the number 
of parallel bands significantly decrease with increasing interpass temperature, while the changes in convex bands is the exact opposite. For the deposit produced using forced interpass cooling, the area of convex bands regions is almost equal to that of parallel bands regions, as shown in Fig.6d and Fig.7. The vertical spacing of the bands in the parallel and convex regions of the deposit produced using forced interpass cooling is visibly greater than the spacing of the bands seen in any of the other deposits, considered to be a result of consistently higher cooling rate.
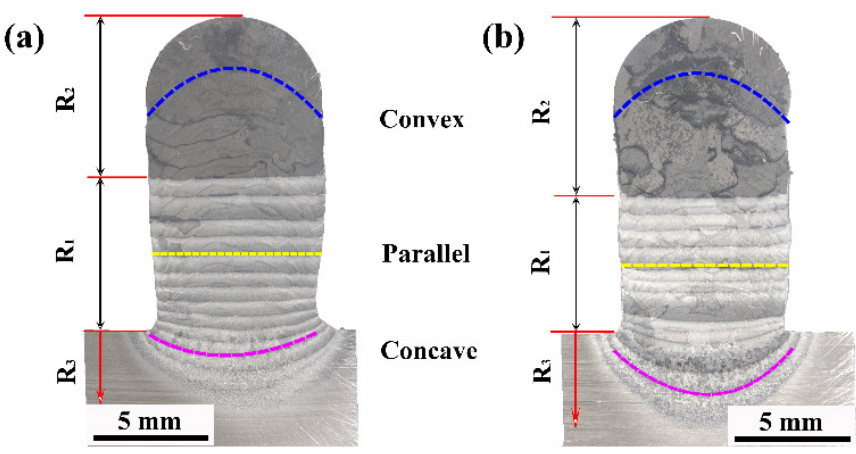

(c)
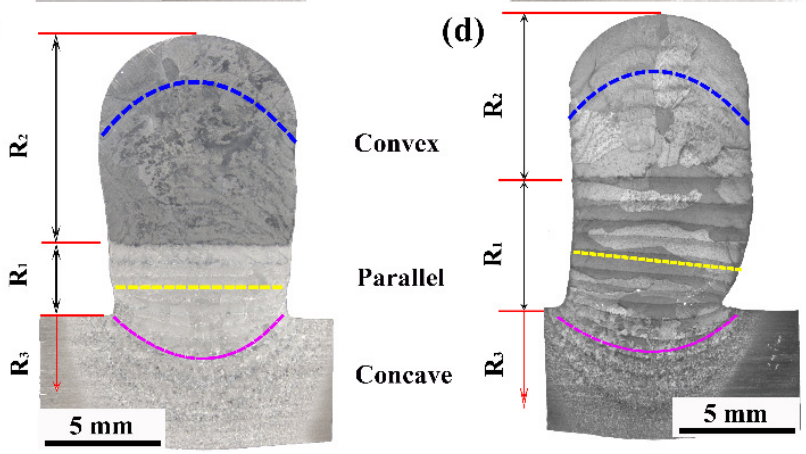

Fig.6 The cross-section morphology of Ti6Al4V component fabricated at : (a) $100{ }^{\circ} \mathrm{C}$; (b) $200{ }^{\circ} \mathrm{C}$; (c) $300{ }^{\circ} \mathrm{C}$; (d) forced interpass cooling with $\mathrm{CO}_{2}$ gas 


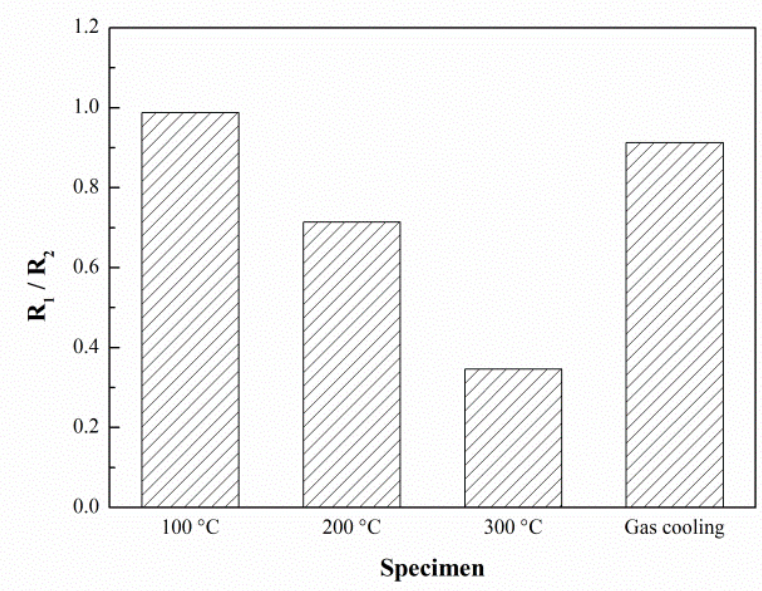

Fig.7 The area ratio of parallel band regions and convex band regions for different process conditions

\subsection{Microstructure}

Fig.8 shows the microstructure of the as-fabricated Ti6Al4V parts, examined along the building direction. Due to the influences of thermal gradient and solidification rate, near-equiaxed beta grains (Fig.8a) are formed in the substrate regions, lamellar $\alpha$ interwoven with a coarse Widmanstätten structure are produced in the parallel band regions (Fig.8b), and acicular $\alpha$ interwoven with a basketweave structure are generated in the convex band regions (Fig.8c). Similar microstructural evolution has been reported for fabrication using electron beam deposition (Tan et al., 2015) and laser additive manufacturing (Mower and Long, 2016). It is well known that deposited Ti6Al4V mainly consists of $\alpha^{\prime}, \alpha$ and $\beta$ phases, and only $\alpha^{\prime}$ phase is formed at high cooling rates. As can be seen from Fig.8, the microstructures and grain size in parallel and convex band regions are not significantly influenced by interpass temperature, possibly due to the similar heat dissipation behaviour at the same locations within each of the produced parts. However, for convex band regions with 
high interpass temperature, the grains are obviously large and the microstructure is more uniform due to grain growth at low cooling rates. For the part deposited using $\mathrm{CO}_{2}$ gas interpass cooling, comparatively more acicular $\alpha$ phases can be observed in both convex band and parallel band regions. That is to say, when rapid interpass cooling is applied, the large amount of lamellar $\alpha$ phase would be replaced by acicular $\alpha$ phase, at the same time accompanied with refined grain.

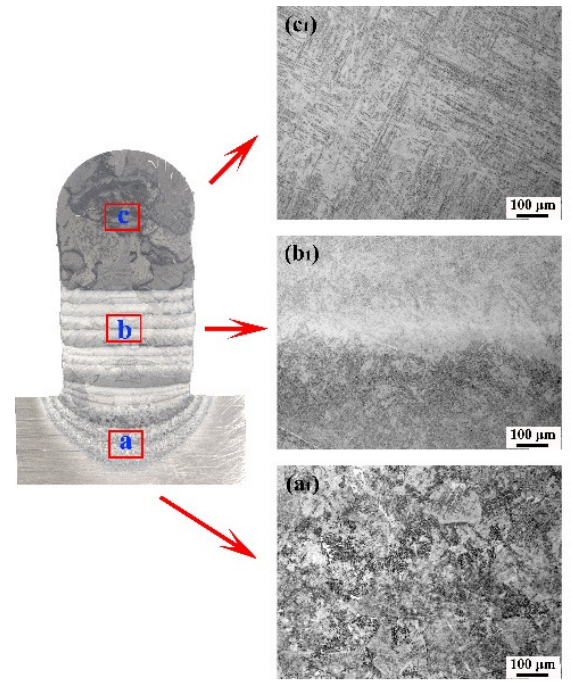

$100^{\circ} \mathrm{C}$
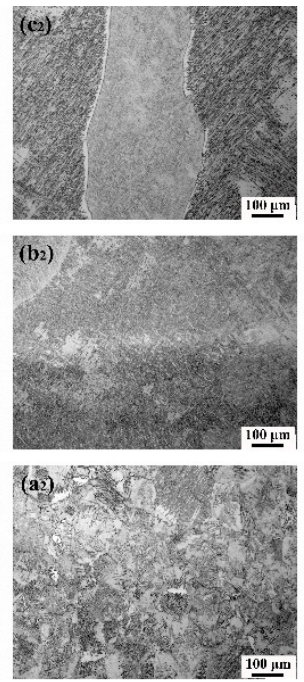

$200^{\circ} \mathrm{C}$

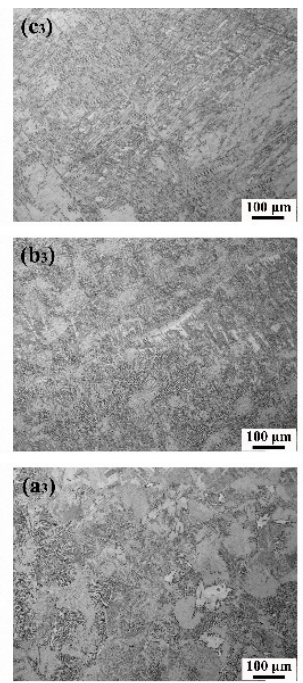

$300^{\circ} \mathrm{C}$

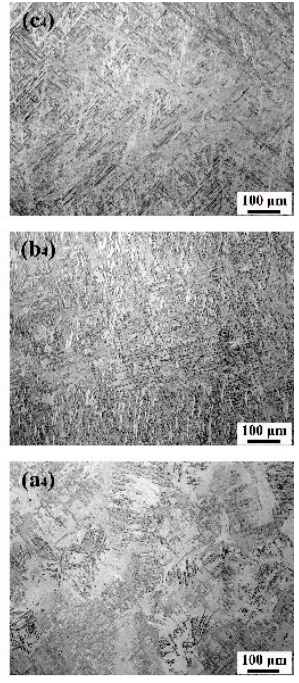

$\mathrm{CO}_{2}$ cooling

Fig.8 The microstructures of parts fabricated under different process conditions

\subsection{Hardness}

Fig.9 shows the microhardness distribution along the vertical centerline of the cross-section of the Ti6Al4V parts fabricated under different process conditions. There is no obvious change in the average hardness values when the interpass temperature is increased from $100{ }^{\circ} \mathrm{C}$ to $300{ }^{\circ} \mathrm{C}$, but the deposition with $\mathrm{CO}_{2}$ gas cooling exhibits a slightly higher average hardness value, which is attributed to comparatively more acicular $\alpha$ phase and grain refinement. Despite the markedly different appearances of band structures in the top and bottom regions, the microhardness is almost unchanged, suggesting that the difference in $\alpha$ phase volume 
is not responsible for the hardness performance, as similarly explained by Baufeld et al. (2011).

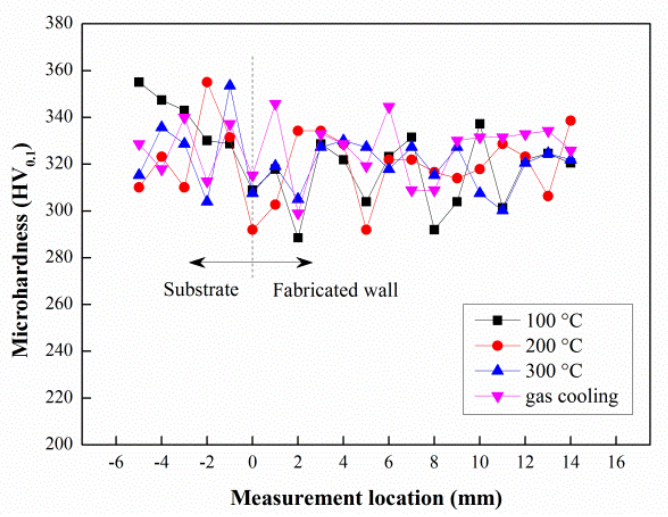

(a)

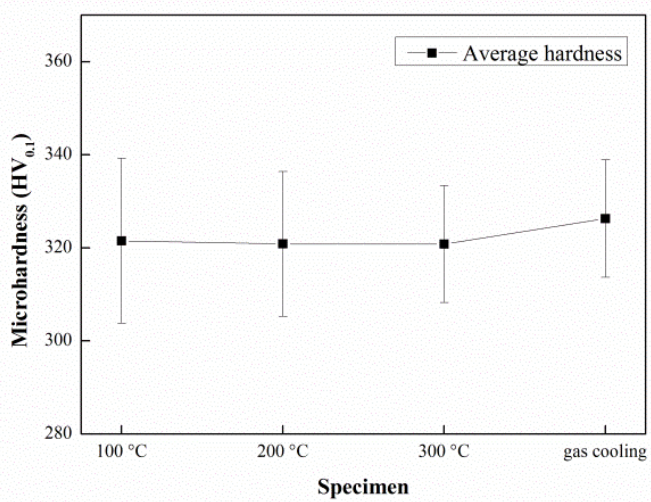

(b)

Fig. 9 Hardness profiles of specimens: (a) Hardness distribution; (b) Average hardness

\subsection{Mechanical properties}

Fig.10 shows the ultimate tensile strength (UTS) and elongation of tensile specimens derived from different locations within the four parts produced under different process conditions. The UTS is sensitive to the locations within the build, decreasing along the build height even though the various interpass temperatures were controlled throughout the build height, as seen in Fig.10a. However, the elongation of these tensile specimens shows a slight increase and then a decrease from bottom to top of the deposit, as shown in Fig.10b. From both of these results it is evident that the mechanical properties are asymmetrical within the WAAM deposit. In addition, as a result of the combined effects from grain size and oxidation behaviour, a significant decrease in both average tensile strength and elongation is observed with increasing interpass temperature (Fig.10c). The deposit produced with additional $\mathrm{CO}_{2}$ gas interpass cooling shows slightly higher UTS and lower elongation compared to those deposits produced without forced cooling, suggesting that interpass cooling is 
beneficial to the material properties of WAAM-fabricated Ti6Al4V components.

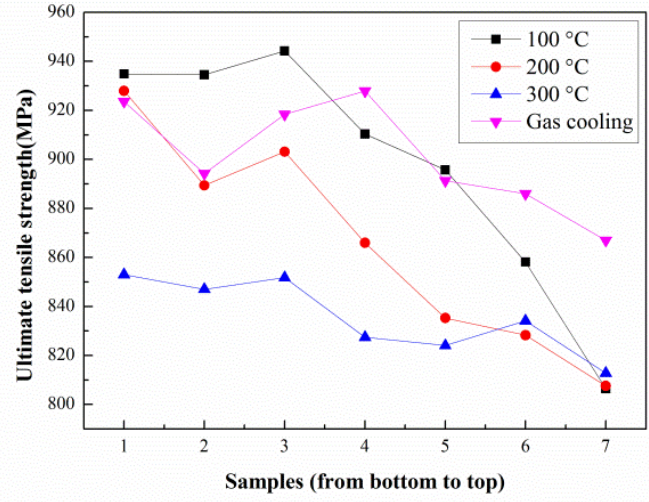

(a)

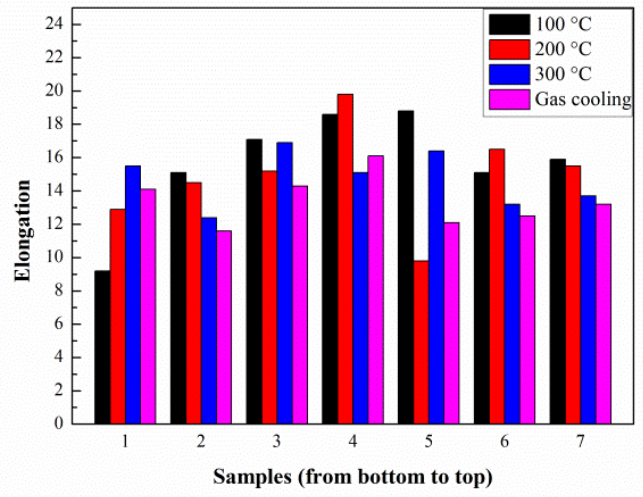

(b)

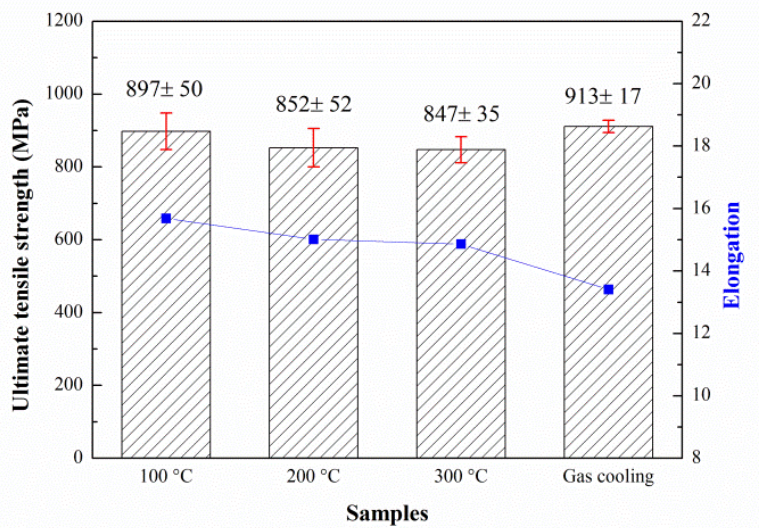

(c)

Fig. 10 The mechanical properties of obtained specimens

\subsection{Fracture behaviour}

Fig.11 displays the fractographs the tested tensile samples. All the tensile samples present ductile morphology with a large number of shallow and stretched dimples in response to fracture. There is no significant difference in the fracture features among all the components that have been produced with different process conditions. However, the fracture surface of the specimen fabricated with an interpass temperature of $300{ }^{\circ} \mathrm{C}$ presents small amounts of lamellar structures, indicated within the red rectangle in Fig.11c, which demonstrates rapid crack growth along the crystallographic planes. 


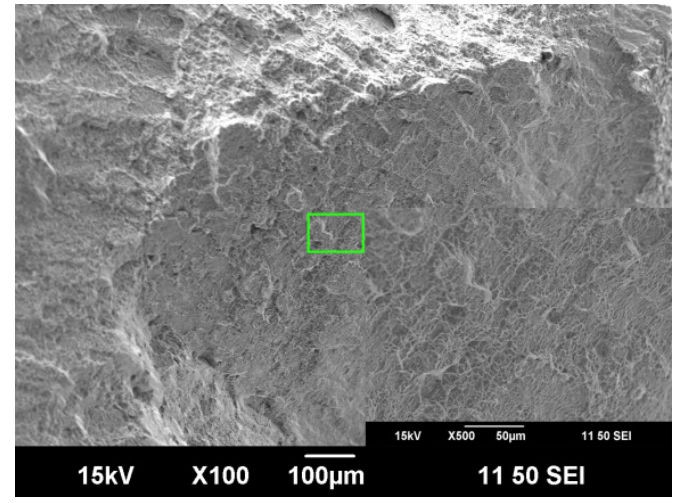

(a)

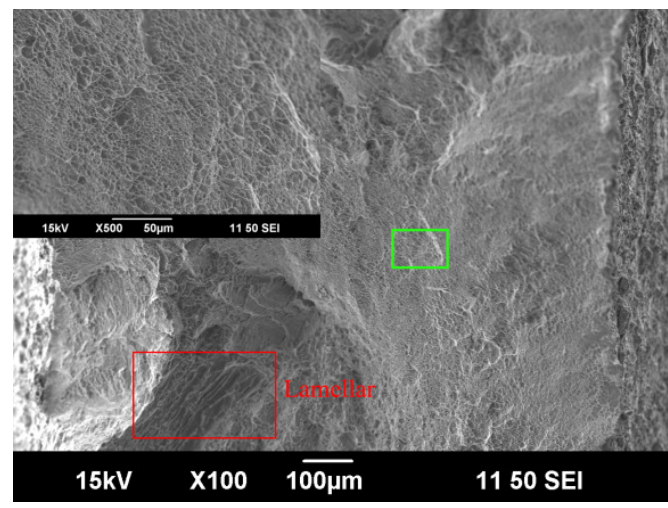

(c)

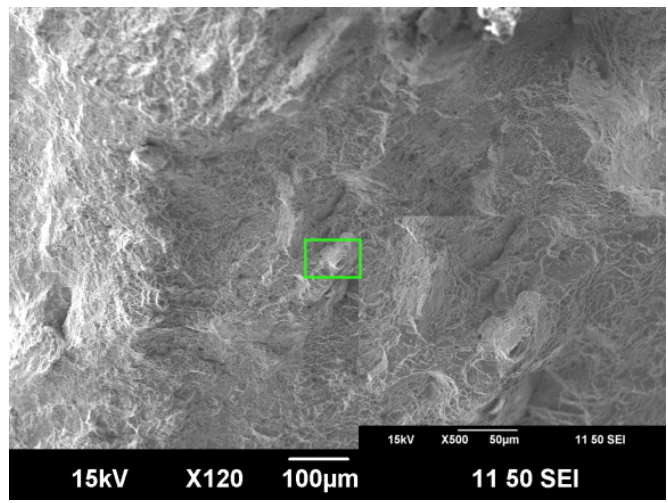

(b)

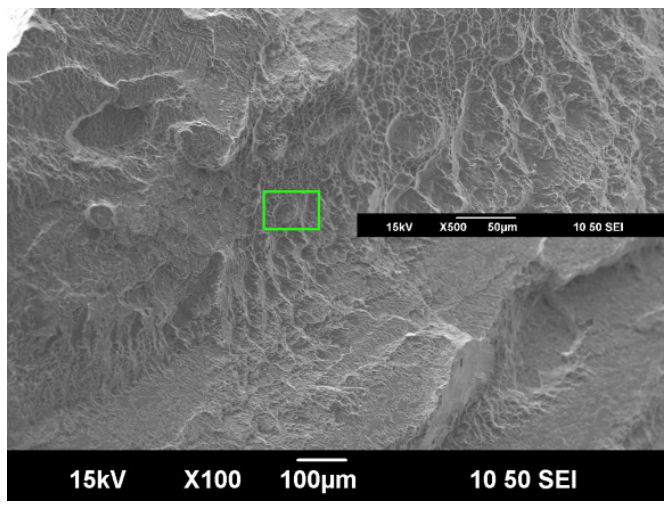

(d)

Fig.11 High-magnification fractographs of tensile samples: (a) $100{ }^{\circ} \mathrm{C}$; (b) $200{ }^{\circ} \mathrm{C}$; (c) $300{ }^{\circ} \mathrm{C}$; (d) Interpass $\mathrm{CO}_{2}$ gas cooling

\section{Discussion}

Based on the results presented in the previous section, the influence of in-process interpass temperature on the deposition geometry, surface oxidation and mechanical properties is significant, but there are no obvious changes in the microstructural evolution and hardness values. The use of forced interpass cooling discernibly improves the material properties, which suggests that the overall material properties of Ti6Al4V components, in this case, may be better controlled during the WAAM process.

It is accepted practice to visually inspect the surface additively manufactured Ti6A14V parts for coloration and surface imperfections, as this gives an indication of 
the effectiveness of the inert gas shielding envelope against atmospheric contamination (Hong and Shin, 2016). In this study, the localized gas shielding is only effective for the most recently deposited layers. Generally, the unshielded part is easily oxidized when depositing. As found from experimental results, when a low interpass temperature of $100{ }^{\circ} \mathrm{C}$ is used, significantly less oxidation is generated on the exposed deposition surface. The low initial component temperature results in a sufficiently low final surface temperature (after deposition of the next layer) so the rate of oxygen diffusion into the surface is slow enough that significant coloration does not occur after the shielding gas flow is stopped. When the interpass temperature is increased, oxygen diffusion into the unshielded surfaces of the part progressively increases and is visibly indicated by surface coloration, accompanied by deteriorating bulk material properties. When using $\mathrm{CO}_{2}$ gas interpass cooling, clean fabricated surfaces are achieved, with only very light oxidation, as indicated by a faint straw color. This demonstrates that interpass cooling is an effective method for minimizing surface oxidation in WAAM using localized gas shielding, while also significantly reducing the interpass dwell time. WAAM fabrication of highly reactive metals usually involves the use of a closed chamber containing an inert gas atmosphere. This imposes severe constraints on equipment operation and maximum component size, as well as the inability to introduce other production aids such as $\mathrm{CO}_{2}$ gas cooling to reduce production times. This study proposes an effective method for fabricating reactive metals such as Ti6Al4V using localized gas shielding in an open environment, while being able to produce components with acceptable properties. This could play 
an important role in reducing processing times and cost of production and improving manufacturing efficiency.

Although high interpass temperature for fabrication means less dwell time and hence higher effective deposition rate, the experimental results have shown that the layer geometry is significantly different to that produced at interpass temperatures closer to room temperature. Unless this effect is faithfully modelled by the WAAM path planning algorithm and compensatory steps are taken, the geometrical accuracy of the produced part will be poor. Hence, the interpass temperature should be considered in the path planning process for depositing and needs to be controlled during the manufacturing process. This may need to include the initial additive deposit on the substrate. Although this aspect has not been studied here because it would be considered as pre-heating, it may be necessary to avoid the geometrical inaccuracies that are often produced in the first few layers. Alternatively, the WAAM deposition parameters for the first few layers will need to have an effectively higher ratio of heat input to produce the desired geometry.

With reference to the distribution of band structures seen in the cross-sectional macrographs of the deposited parts, Baufeld et al. (2010) have claimed that material taken from top regions of deposits exhibiting convex bands is much weaker than material taken from bottom regions exhibiting parallel bands. This is in agreement with the tensile results obtained in this study. As the interpass temperature increases, more convex bands develop, leading to an increased area with inferior mechanical properties. However, more deposition layers can be visible since these convex bands 
form in association with layered bulges which represent the liquids of subsequent WAAM steps, as indicated by Baufeld et al. (2009). The proportion of the deposit containing parallel bands is reduced as the interpass temperature increases, indicating a reduction of build area with comparatively superior mechanical properties. It should be mentioned that these parallel bands perform inconsistency with visible deposition layers, which is evident by their end in the indentation between layered bulges (Baufeld et al., 2010). For this case, forced interpass cooling is considered as an effective way to increase the number of parallel bands, as shown in Fig.6 and Fig.7., and the resulting effects are even better than those for the manufacturing process with low interpass temperature achieved from natural cooling, due to the widening of band structures at higher cooling rates.

Referring to material properties, interpass temperature only has a small effect on the microstructures, but it has been observed that rapid interpass cooling causes more grain refinement, producing correspondingly better performance in hardness and mechanical properties. The hardness of WAAM-fabricated Ti6Al4V is mainly determined by solid solution and grain boundaries or dislocation distribution due to some segregated elements interacting between grain boundaries, and edge dislocations existing in $\alpha / \beta$ microstructures (Brandl et al., 2012). When forced interpass cooling is used, the deposit cools down faster than for the case of natural cooling, which thus brings more grain boundaries and dislocations to produce higher microhardness values (Welsch et al., 1993). Furthermore, the Ti6Al4V microstructure obtained at high cooling rates consists of large amounts of massive $\alpha$ phases with acicular 
appearance and non-equilibrium composition, which are usually harder and have higher strength than those produced at lower cooling rates. For the same reason, forced interpass cooling produces deposits with higher hardness. It should be mentioned that the massive $\alpha$ phase has similar crystalline structure to lamellar $\alpha$ phase and has similar chemical composition to $\beta$ phase (Charles, 2016), which contributes to the hardness being uniformly distributed in the integral part even when the process conditions are changed.

Another benefit of forced interpass cooling is that for Ti6Al4V $\alpha+\beta$ structures, high cooling rate and rapid solidification rate are also expected to increase the $\beta$ phase, helping to make the phase distribution more easily approach the equilibrium (around 5\% $\beta$ phase and 95\% $\alpha$ phase) (Welsch et al., 1977). Therefore the material strength, in a manner, is enhanced.

From the discussion part, it is apparent that what this study prefers to display is a comprehensive analysis of WAAM printed Ti6Al4V alloy with forced interpass cooling using compressed $\mathrm{CO}_{2}$. It is believed that the proposed innovative process is beneficial to the fabricated part. In near future, the best practices for applying interpass cooling and localized gas shielding will be continued.

\section{Conclusion}

In this study, Ti6Al4V alloy has been used as the build material for the GT-WAAM process using localized gas shielding. The effects of various interpass temperatures and $\mathrm{CO}_{2}$ gas interpass cooling on the bead geometry, surface oxidation, microstructural morphology, grain size, mechanical properties and fracture features 
were investigated. The findings include:

(1) In terms of microstructural evolution and hardness, the properties of WAAM-fabricated Ti6Al4V components are measurably different but not greatly affected by variation of the interpass temperature. However, it is still necessary to control interpass temperature to a reasonable range to ensure the geometric accuracy of each deposited layer and to avoid surface oxidation.

(2) Forced interpass cooling using compressed $\mathrm{CO}_{2}$ gas is easily implemented, and is beneficial to additively manufactured Ti6Al4V components, contributing to an appealing surface finish with less visible surface oxidation, refined microstructure, improved hardness and enhanced strength.

(3) WAAM deposition with $\mathrm{CO}_{2}$ gas interpass cooling significantly promotes manufacturing efficiency through a sharp reduction of dwell time between the deposited layers.

Further investigations will focus on the effects of different cooling gas flow rates and various cooling times on the deposition properties in order to validate the effectiveness of this process. In addition, quantitative temperature measurement using IR pyrometry will be used to explore the thermal behaviour during deposition with interpass cooling. The residual stress and deformation of WAAM fabricated components will also be presented in near future.

\section{Acknowledgements}

The authors would acknowledge the China Scholarship Council for their finical support (NO. 201506680056). 


\section{References}

Baufeld, B., Biest, O.v.d., Gault, R., 2009. Microstructure of Ti-6Al-4V specimens produced by shaped metal deposition. Int. J. Mater. Res. 100, 1536-1542.

Baufeld, B., Biest, O.V.d., Gault, R., 2010. Additive manufacturing of Ti-6Al-4V components by shaped metal deposition: Microstructure and mechanical properties. Mater. Des. 31, Supplement 1, S106-S111.

Baufeld, B., Brandl, E., Van der Biest, O., 2011. Wire based additive layer manufacturing: comparison of microstructure and mechanical properties of Ti-6Al-4V components fabricated by laser-beam deposition and shaped metal deposition. J. Mater. Process Technol. 211, 1146-1158.

Brandl, E., Schoberth, A., Leyens, C., 2012. Morphology, microstructure, and hardness of titanium (Ti-6Al-4V) blocks deposited by wire-feed additive layer manufacturing (ALM). Mater. Sci. Eng., A 532, 295-307.

Charles, C., 2016. Microstructure model for Ti-6Al-4V used in simulation of additive manufacturing (Doctoral dissertation). Luleå tekniska universitet.

Collins, P.C., Brice, D.A., Samimi, P., Ghamarian, I., Fraser, H.L., 2016. Microstructural control of additively manufactured metallic materials. Annu. Rev. Mater. Res. 46, 63-91.

Ding, D., Pan, Z., Cuiuri, D., Li, H., 2015. A practical path planning methodology for wire and arc additive manufacturing of thin-walled structures. Robot. Comput. Integr. Manuf. 34, 8-19.

Foster, B., Beese, A., Keist, J., McHale, E., Palmer, T., 2017. Impact of interlayer dwell time on microstructure and mechanical properties of nickel and titanium alloys. Metall. Mater. Trans. A 48, 4411-4422.

Henckell, P., Günther, K., Ali, Y., Bergmann, J.P., Scholz, J., Forêt, P., 2017. The influence of gas cooling in context of wire arc additive manufacturing- a novel strategy of affecting grain structure and size, TMS 2017 146th Annual Meeting \& Exhibition Supplemental Proceedings. Springer, pp. 147-156.

Herzog, D., Seyda, V., Wycisk, E., Emmelmann, C., 2016. Additive manufacturing of 
metals. Acta. Mater. 117, 371-392.

Holder, R., Larkin, N., Li, H., Kuzmikova, L., Pan, Z., Norrish, J., 2011. Development of a DC-LSND welding process for GMAW on DH-36 Steel. 56th WTIA annual conference. pp. 1-13.

Hong, K.-M., Shin, Y.C., 2016. Analysis of microstructure and mechanical properties change in laser welding of Ti6Al4V with a multiphysics prediction model. J. Mater. Process Technol. 237, 420-429.

Mower, T.M., Long, M.J., 2016. Mechanical behavior of additive manufactured, powder-bed laser-fused materials. Mater. Sci. Eng., A 651, 198-213.

Pan, Z., Ding, D., Wu, B., Cuiuri, D., Li, H., Norrish, J., 2018. Arc welding processes for additive manufacturing: A Review, In: Chen, S., Zhang, Y., Feng, Z. (Eds.), Transactions on Intelligent Welding Manufacturing, Vol. 1, No. 1. Springer Singapore, Singapore, pp. 3-24.

Suryakumar, S., Karunakaran, K., Chandrasekhar, U., Somashekara, M., 2013. A study of the mechanical properties of objects built through weld-deposition. Proc. Inst. Mech. Eng., B J. Eng. Manuf. 227, 1138-1147.

Tan, X., Kok, Y., Tan, Y.J., Descoins, M., Mangelinck, D., Tor, S.B., Leong, K.F., Chua, C.K., 2015. Graded microstructure and mechanical properties of additive manufactured Ti-6Al-4V via electron beam melting. Acta Mater. 97, 1-16.

Welsch, G., Boyer, R., Collings, E.W., 1993. Materials properties handbook: titanium alloys. ASM International.

Welsch, G., Bunk, W., Kellerer, H., 1977. Einfluß von Spannungsfrei - Glühung und Abkühlungsgeschwindigkeit auf Mikrostruktur und Festigkeit von TiAl6V4. Materialwissenschaft und Werkstofftechnik 8, 141-148.

Williams, S.W., Martina, F., Addison, A.C., Ding, J., Pardal, G., Colegrove, P., 2016. Wire + Arc Additive Manufacturing. Mater. Sci. Technol. 32, 641-647.

Wu, B., Ding, D., Pan, Z., Cuiuri, D., Li, H., Han, J., Fei, Z., 2017. Effects of heat accumulation on the arc characteristics and metal transfer behavior in Wire Arc Additive Manufacturing of Ti6Al4V. J. Mater. Process Technol. 250, 304-312. 